\title{
A New Interpretation of Family Education under Sociological Perspective
}

\author{
Yanjin Liu, Xuntao Yue \\ College of Education of Chengdu Normal University, Chengdu, China \\ Email: hnlyj1999@126.com
}

How to cite this paper: Liu, Y.J. and Yue, X.T. (2018) A New Interpretation of Family Education under Sociological Perspective. Open Journal of Social Sciences, 6, 144-153. https://doi.org/10.4236/jss.2018.65012

Received: April 26, 2018

Accepted: May 21, 2018

Published: May 24, 2018

Copyright $\odot 2018$ by authors and Scientific Research Publishing Inc. This work is licensed under the Creative Commons Attribution International License (CC BY 4.0).

http://creativecommons.org/licenses/by/4.0/

\begin{abstract}
In Education, family education is a vague concept, for its lack of comprehensive account for what it is and how it is doing. Therefore the study of it from the perspective of educational sociology enriches the connotation of family education, as well as its denotation. The new interpretation of family education will strive to present a more complete picture of family education, and explain the rationality and richness of family education, while avoiding the limitations and misunderstandings in the understanding.
\end{abstract}

\section{Keywords}

Sociological Perspective, Family Education, New Interpretation

\section{Introduction}

The most basic elements of individual growth consist of family, school and society. The study of the relationship between family and education is not only a traditional subject of general pedagogy, but also a major concern of educational sociology. In the view of general pedagogy, the understanding of the relationship between family and education is highlighted by the emphasis in school education and the close cooperation with family education, especially in school moral education; more attention is paid to the consistency of school education, family education and education in the society, emphasizing the multi-pronged, mutual cooperation to promote the development of students. However, in pedagogy, family education is a relatively obscure concept, and lack of comprehensive explanation for what is and how it is. Therefore, when it comes to family education, there seems to be no more or more definite discussion than its importance, no matter in the teacher's understanding, or in that of the parents'. The only consensus is: where there is family, there is education. The existing family edu- 
cation mainly focuses on individual issues such as parents' exemplary teaching, education attitude and methods, While it puts forward notions and patterns about what parents "have done" and "should do", the understanding and analysis of the family itself as the source of education lacks comprehensive and substantive research. This study will explore the concept of family education from the perspective of sociology, not only to fully understand the connotation and education function of family education, but also to provide a reference for the comprehensive understanding and cognition of family education.

\section{The Developing New Interpretation of Family Education}

In the book "Family as an educational factor", American sociologist H.J. Rekt points out that the more education is valued, family, as an important source of education will be more concerned. New technology revolution and the information explosion led to the great change of family education, from scale to structure, from function to concept, putting the complexity of modern family relationship with education in compelling and thought-provoking changes. Today, people are not satisfied with the close relationship between family and education, but more willing to explain the overall relationship between family and education theoretically. Hence in the perspective of educational Sociology, it is necessary to examine the relationship between family and education in a comprehensive way from a new perspective, compared with the existing theory, redefine family education, explore its rich connotation and educational function, as well as further analyze the specific effects of different family environment factors in the process of Children's academic development, personalization and socialization, and then proceed from the reality of Chinese family education, provide opinions and strategies of educational sociology to improve the quality of family education from the perspective of educational sociological research on family problems.

Further comparing the traditional view of family education with the modern view, it can be found that the connotation of family education is changing. Traditional family education involves four aspects: One is that parents set an example for children and use the power of example (including one's ideology, personality and cultural quality) to influence the development of children, as Marco Jien Co said "A parent's requirements to himself, respect for his family, and attention to every behavior, is the first and for most method of education for children." This type of silent family education is often more powerful than the sound education, which is the sense of achievement education. The second is to use the mother tongue correctly in the family, to improve the Children's feelings and understanding of the mother tongue, and to enrich the Children's vocabulary. The mother tongue is usually one's earliest contact, learning, and mastery of a language, and lasts for a life time. One's early education, especially family education, was mostly taught in the mother tongue, or in other words, mother tongue education. The third is to show the children the example of etiquette and 
manner of dealing with people. Children have the instinct to imitate, so parents' etiquette behavior, such as dealing with people, will deeply affect the development of Children's communication ability, making them gradually understand the meaning of civilization, courtesy and enthusiasm in the environment of osmosis, so as to lay the foundation for the normal social life in the future, namely, etiquette education. The fourth is to correctly guide the children to carry out self-service labor and housework, cultivate the concept of labor and common sense, and the consciousness and ability of living independently, namely, work education.

Compared to traditional family education, modern family education is not only more abundant in content, but also promoted in form. The change of modern family education embodies in: Firstly, creating a cultural space of the family, constructing a cultural, artistic and scientific family life, which invariably affect, edify, enrich and cultivate children's spiritual world, and instill child's spiritual morality, value orientation, civilized quality and behavior, namely, the construction of family cultural environment. Secondly, allowing children to experience the society and life, accompanied by parents, and practice open education, help them perceive and understand the society through social activities, get to know about themselves, others and also the society and the environment, accumulating life experience, namely the education that attaches great importance to life experience. Third, taking their children to participate in the community activities, to learn to love the neighborhood, respect the old and love the young, help the people in need, to establish a good social relations, namely, gratitude education. Fourthly, family and school establish a cooperative education relationship, so as to understand the students' role, adjust the learning tension and learning motivation, and make education expansion in the possible situation. That is to attach importance to the family school union, namely, synergistic education.

It can be seen from the changes mentioned above between the traditional family education view and the modern view that traditional family education pays more attention to the one-way, periodical, emerging, regular and sound education, while modern family education pays more and more attention to the construction and improvement of recessive education resources, such as cultural environment, atmosphere, interpersonal relationship in the family, cultural values, attitudes, habits, etiquette, beliefs, prejudices, taboo and the like, in the social environment, and more importantly, focuses on exemplary education of parents, elders and older people, and at the same time pays attention to the mining of potential and lifelong development of children. Therefore, in order to depict a full view of family education, and make a comprehensive explanation to family education from the perspective of educational sociology, it is necessary to research the existing concept of family education, including its rationality and limitations.

\section{Limitation of the Existing Family Education Theory}

The generally accepted definition of family education can be seen in Encyclope- 
dia of China, Education Volume: "Family education refers to the education that parents or other elderly people give to their children conscientiously and hierarchically in the family." [1] and in Comprehensive Dictionary of Education: "Family education refers to the education among family members. It usually refers to the education that parents or other elders give to their children." [2] In addition, several similar expressions are found: "Family education is education for children and adolescents in the Family from parents or other elders of the Family." [3] "Family education refers to parents' education for their children according to certain standards." (November 15, 1971, Announcement of the ministry of culture of Japan's ministry of social education) [4]. Family education is a targeted, systematic and organized educational activity that parents and other elders in the family carried out on children and adolescents [5]. It is reasonable to say that these concepts are consistent with people's general view of family education. In experience, it is common for people to think that a family education must be visible, and that it is a serious, face-to-face dialogue the "upper" role of the parents have with the "underneath" role of the children on certain issues. In this kind of education, the main content is to inform and admonish. Through this education, parents have to explicitly teach their children what to learn or influence their children. However, this understanding of family education is obviously not comprehensive. Although it embodies the deserved state of family education, which is why it is also a reasonable part of the concept of family education, and is easy to be accepted as a consensus, but the concept cannot reflect the real state of family education in a comprehensive and objective way, and cannot meet the needs of educational sociology to understand the needs of family education by the attitude of empirical research. Nowadays, the above definition has multiple limitations, and may cause misunderstanding, which mainly displays in three aspects:

\subsection{Customarily Limit the Role of Educator in Family Education to Parents and Elders}

As family members, parents and children are important elements of family. Although there's distinct order in age in family, there's no rule for role status. In China, there is a feudal old adage, "the father is the sub-outline", which is terrible; and because of intergenerational reasons there are natural pecking order between parents and children, and must be maintained as unalterable principles. According to the modern concept, order in age in the family does not determine the parent's absolute authority. In the family, both parents and children can be each other's educators and educatees, and it is inappropriate to think that only parents' influence on their children is education. It should be acknowledged that "Parents are the first teachers of children", but that is not to say that only parents can serve as teachers, and children can only be obedient. In family, parents' role as teachers or students shouldn't be absolutized, instead, it is also inevitable that the role of parents and children may be interchangeable under certain circums- 
tance. Growing up with children, the socialization process of children is often the second socialization process of parents, which indicate that children can also become parents' teachers. Children's growth is a gradual process of maturity, in the process of which the problems encountered in the development of children can encourage parents to reflect on their own educational gains and losses, and then improve the education level of parents. The parental role is achieved because of the children. The birth and growth of children inevitably requires parents to re-establish their new role consciousness and behavior and experience their second socialization as individuals. In the second socialization process, they have to complete a lot of role transformation and experience the transition of the psychological state from the unconscious role to the conscious role, including the transition from the role of the child to the role of the parent, and other transformation of the role accompanied by this.

When children enter the school, the parents change to the role of parents compared to the school teachers, and the communication between teachers and parents reflects the cooperation between the schools and the families. When the children are in the non-school environment, the role of the parents should highlight the status as guardians, and for the social adaptation of the children, the parents should become the important social companions of the children. When children are about to enter the society and live independently, parents take on the role of the professional mentor for the children. In a word, the joy and annoyance of the Children's growth can be vivid teaching materials for "parental education". For the parents, they experience the role of the educated while experiencing the role of parents, and become one who desires to be more mature and rewarding, like the students. Therefore, family education is not only the parents' education for children, but also the educational impact of various facts, consisting of Children's behavior, attitude and emotion, on their parents. That is, the relationship between parents and children in family education is multidirectional and interchangeable-parents and elders are not only the condescending educators, but they should also be educated and receive the education and influence of their children. These understandings are also very similar to the current new view that "family education is also a parental education".

\subsection{Lack of Awareness of the Disorder in Family Education}

Self-consciousness and hierarchy are an orderly performance, while the education phenomenon in family life is not completely conscious and hierarchical. So, disorder is the norm of family education. The existence of a family is closely related to the survival and lifestyle of family members. In family life, education is permeated and attention must be paid to this permeable educational phenomenon. In parents relationship with children, its randomness and arbitrariness in communication make family education inadvertently happen in natural state. In his observational learning experiment, psychologist Bandura demonstrated that children can learn the same behavior by observing the exemplary behavior of 
role models. Any unintentional words and behaviors of parents in the family may become the object of Children's imitation, which results in Children's observation and study. As educator Marco Jien Co said: “Don't think that you are educating the children only when you talk with them, teach them and command them. You are educating them in every moment of life, even when you are not around. How you wear, how you talk to others or talk about others, how you express happiness and worries, how you treat friends and enemies, how you laugh and how you read newspapers-all of these are of great significance for children." In family life, when a child is facing criticism from his parents, it is time for parents to review their role models when children "do evil for evil act". In fact, don't blame Children's "chicanery" or "sophistry", the behavior of parents inadvertently triggered an involuntary impulse. At this point, the Children's imitation of parents' behavior is a "master card" to protect themselves. The parents' "misbehavior" results in "disobedient" or even "act in contravention", although it is contrary to the original intention of family education, it also the result of the parents "improper behavior". Therefore, it is not enough for family education to focus on parents' conscious education.

In fact, it is difficult to distinguish the conscious or unconscious phenomenon of family education. It can be argued that the non-conscious characteristics of family education are more prominent in family life, as seen from the mutual influence of family members, in particular, the influence of parents on their children. When their children show more serious problems, or when something special happens to them in their studies and their lives, when corresponding care and advice are needed in different age stages of their growth, the parents' family education of their children may show obvious consciousness. Therefore, the understanding of family education should not be limited to parents' conscious behavior.

The notion that family education is parents' hierarchical education for their children is too one-sided. Hierarchical education reflects parents' rigorous and serialized consideration of the purpose, content, methods, and means of family education. There are clear educational intentions for Children's problems and phenomena occurring at different ages and under different conditions. However, the randomness and arbitrariness of family education have broken the hierarchy of family education. No matter how rational the parents are, how thoughtful the family education is, as long as they collide with the actual situation, the rhythm and order of education may be changed, so the family education can not completely take on the hierarchical pattern.

\subsection{Ignoring the Environmental Effect in Family Education}

The impact that family education can produce is not only reflected in the interactions among family members. More often than not, when a child is placed in a family environment where he cannot choose or even get rid of, the impact of these factors will not as the parents are not in front of him and change, "home 
education is not limited to specific forms, no courses, no places, education in the eyes of the students." In other words, the family factor is presented in the family education in a state of "no subject". Once the children are in a certain family environment, the influence of the family is ubiquitous at any time, and even if no visible person in the family exerts influence on them, there is still an invisible "environmental" educational effect. In the present concept of family education, it is flawed to emphasize only the influence of parents on the "subject" of Children's education while ignoring the "non-subjective" influence of the family environment.

In a word, there is a clear gap between the theory and the facts of family education, such as parents are not the only educators in the family; parents cannot get rid of the non-conscious and non-hierarchical side of their Children's education; parents' influence on Children's education is coexisting with the "no-subject" role of the family environment, and so on. The explanation of family education in traditional theory cannot cover the whole intention, phenomenon and spontaneous component of family education. Therefore, the extension of family education in traditional theory is also artificially restricted.

\section{New Concept of Family Education from the Perspective of Educational Sociology}

Educational sociology has new content in the function and characteristics of home education. This understanding comes from understanding the situation on the site. The richness and diversity of life presents people with far more phenomena than the laboratory and also differs from what the sample survey can achieve. Being exposed to the actual and dynamic reality, the sociological researcher's gains differ from that of the users of other research methods.

Educational sociology tends to examine the interaction between family and education from a macro perspective. Therefore, the concept extension of family education will be broadened and its connotation will be enriched. Analyzed from the perspective of sociology, family education refers not only to the education generated in the family, but also to the role of family environment in education. This understanding of family education goes beyond the limitations of traditional concepts, so that people can fully understand the different aspects of family education, explore and excavate the deeper and wider significance and role of family education. The main manifestations are as follows:

\subsection{Emphasizing the Bidirectional Nature of Family Education}

In the new concept of family education, the "subjective" influence between family members is placed on the same platform. Both the elder's influence on juniors and the family's are excluded. There are certain problems and aspects of younger generations. The influence of elders. It can be seen in the family that parents will use the family dialogue to understand what they don't know about, including fashion topics in the mass media, the information technology that is 
now popular, and so on, which can make up for the limited time and energy generated by parents. Lack of communication. When a parent accuses a child of an unprovoked conduct and the child excuse or fight against it, this state is what the younger generation educates. Children use this opportunity to allow parents to learn to self-control, and the quality of self-control is precisely a manifestation of a person's good emotional ability. This kind of "reverse" family education will happen often. Extending family education to two-way interaction between family members makes it possible for parents and children to communicate in mutual respect and mutual understanding. Only by recognizing the "educator" role of children in the family can parents establish the personality equality between parents and children, create an equal and democratic family atmosphere, establish a harmonious parent-child relationship, so as to set up a good image of parents and improve the quality of family education.

\subsection{Highlight the Rationality and Permeability of Family Education}

In family education, rationality reflects the "conscious and hierarchical" aspect of family education, which is the proper state of family education, while permeability is the actual situation of family education, which is the objective performance of the "disorderliness" of family education. The influence of self-consciousness is ideal and rational, and the effect of non-self-consciousness is realistic and universal. These two types of education always exist together. The integrity of family education needs to take into account the influence of self-consciousness and non-consciousness. Traditional family education advocates experience, but family education experience is more individual and typical. This kind of experience is the educational experience of different families, including success and failure. If education is conducted according to the experience of others or the so-called traditional experience of one's own, for children in a changing era, family education may fall into the quagmire of empiricism and lack the quality of the times.

From the sociological point of view on social change, at the same age and in different times, the family education that children can receive must conform to the requirements and characteristics of the present age. Family members, regardless of whether they are older or younger, have different backgrounds and experiences, and the educational factors in their experience cannot be fully adapted to each other's needs. In particular, young parents should get rid of the shackles of experience when it comes to the education of their children, try to promote conscious education. The conscious influence in family education also permeates into family life. Everywhere there is education, as long as parents are interested, there are many educational resources that can be readily used in everyday life situations. When parents and children take a walk, there are many activities that can be consciously done. For instance, seeing trees and birds, parents can carry out mental training for "bird guarding"; seeing the stars and the moon, parents can talk about the legend of "Goddess Change Flying to the Moon" and 
the scientific knowledge of the stars and heavenly bodies; seeing someone trampling on the lawn, polluting the environment, parents can teach children civilized behavior and cultivate Children's good habits. Activities like this, with educational intentions, are only better understood by those who are parents.

\subsection{Embodies the "Subjectivity" of Family Education}

"Subjectivity" is the corresponding aspect of subjectivity. It is intended to show that people's impact on people is the influence of the subject, and the invisible impact is the role of the environment. In this paper, the unseen environmental impact (i.e. the educational effect of the family environment) is called "no subject effect". Parents' family education for their children is the responsibility of parents. However, compared with parents' direct education face to face with children, the family's educational influence on children is more widely infiltrated into the family environment factors created by parents. Children cannot choose their own birth. Of course, they cannot choose their own family environment. Everything in the family, tangible or intangible, direct or indirect, visible or invisible, can constitute an environmental factor affecting the child. Among them, there are subjective factors, such as parents' cultural accomplishment, educational concepts, attitudes and expectations; there are also objective factors, such as the family's economic conditions and social resources. Be them subjective or objective, children must face them in family life. The existence of these environmental factors, there is an educational function attached. However, the educational function of these environmental factors is usually ignored, or not seen at all. As a matter of habit, there should be visible, concrete educators and educatees in the process of education, and parents and children are a pair of concrete concepts. Therefore, to attribute family education to the "subjective" education of parents to their children is not to tap the "non-subjectivity" educational influence produced by family environmental factors. Looking at home education from a complete and updated point of view, in the perspective of sociology of education, more attention has been paid to the "subject-free" education that the family's environmental factors have generated over the child's growth.

\section{Conclusion}

At present, from the perspective of pedagogy, there are three major limitations to the definition of family education, and there is no comprehensive explanation for it. From the perspective of sociology of education, family education is a variety of interaction activities that all members of the family provide to each other. It broadens the concept of family education and enriches the connotation of family education. That is, family education refers not only to education in the family but also to the role of family environment in education. The former refers to a series of conscious or non-conscious, empirical or conscious, tangible or intangible multiple effects exerted on the educatee by family members (whether young or old, but mainly parents); the latter refers to the so-called "no-subject" 
impact of family environment factors such as social background and parenting style. Therefore, only when the original appearance of family education is understood from the perspective of a complete educational sociology, will people have an objective, comprehensive and abundant recognition and understanding of the function of family education.

\section{References}

[1] Editorial Department of China Encyclopedia Press (1985) Encyclopedia of China, Education Volume. Chinese Encyclopedia Press, Beijing, 140.

[2] Compilation Committee of Comprehensive Dictionary of Education (1992) Comprehensive Dictionary of Education. Volume 1. Shanghai Education Press, Shanghai, 11 .

[3] (1994) Encyclopedia of Education. Five South Book Publishing Company, Taipei, 343.

[4] Michiyo, H. (1989) The World Education Dictionary. Huang, D.C., Trans. Hunan Education Press, Changsha, 198.

[5] Yu, M.K. (1991) Education. University of Science and Technology of China Press, Hefei, 317-318. 